\title{
Neurophysiological changes following traumatic spinal lesions in man
}

\author{
S TAYLOR, P ASHBY, M VERRIER \\ From the Lyndhurst Hospital, and Playfair Neuroscience Unit, Toronto Western Hospital, Toronto, Canada
}

SUMMARY Neurophysiological observations were made on normal subjects and on 57 patients who had had injuries to the spinal cord. The amplitude of the muscle compound action potential ( $M$ response) recorded from triceps surae in response to supramaximal stimulation of the tibial nerve was reduced in the patients indicating that there are changes in motor units below the level of a spinal lesion in man. In the patients who were clinically spastic it was found that: (1) The proportion of the triceps surae motoneuron pool reflexly activated either by tapping the Achilles tendon or by stimulating the tibial nerve just below the threshold of the alpha motoneuron axons ( $\mathrm{H}$ reflex) was greater than in normal subjects. This can be explained by an increase in the excitability of central reflex pathways. (2) Vibration of the tendo Achilles depressed the $\mathrm{H}$ reflex less effectively than in normal subjects. This may indicate altered transmission in the premotoneuronal portion of the $\mathrm{H}$ reflex pathway. (3) The $\mathrm{H}$ reflex elicited 50 and $100 \mathrm{~ms}$ after a standardised conditioning stimulus to the tibial nerve and expressed as percentage of the unconditioned reflex was greater than in normal subjects. This could reflect a change in the excitabilit原 of motoneurons or of interneurons.

Spasticity can be defined as "a motor disorder characterised by a velocity-dependent increase in tonic stretch reflexes (muscle tone) with exaggerated tendon jerks". 'The neurophysiological basis for this clinical syndrome is unknown. Most observations on spasticity have been made on mixed groups of patients with cerebral, spinal and diffuse lesions $\mathrm{s}^{2-7}$ although there is no reason to expect that identical neurophysiological abnormalities will result from such anatomically diverse lesions. The simplest form of spasticity is likely to be that resulting from spinal transection, but as yet there are little firm data on the neurophysiological abnormalities in patients with purely spinal lesions. ${ }^{8-12}$ For this reason, we made recordings on a coherent group of patients with spinal cord injuries to determine which neurophysiological abnormalities were associated with spasticity of spinal origin.

\section{Methods}

Subjects

Patients with traumatic spinal cord lesions undergoing

Address for reprint requests: Dr P Ashby, Ste. 203, 25 Leonard Ave., Toronto, Ontario, M5T 2R2 Canada.

Received 11 November 1983 and in revised form 29 March 1984. Accepted 1 April 1984 rehabilitation at a regional spinal injury centre werø examined after obtaining informed consent. Clinical an neurophysiological observations were made at thre stages: on admission (usually 1 month after injury), months after admission, and just prior to discharge. There were six female and 51 male patients aged between 17 and 77 yr (mean $32 \mathrm{yr}$ ). Normal data were obtained from 21 normal subjects -10 female, 11 male aged between 19 and $42 \mathrm{yr}$ (mean $29 \mathrm{yr}$ ).

\section{Clinical assessment}

A clinical assessment was carried out just before the neurophysiological testing. Patients were classified as "flaccid" if (1) their lower extremities could be moved passively (both slowly and rapidly) without eliciting any stretch reflex as detected by an increase in resistance to passive movement or a visible contraction of the stretched muscle and (2) the tendon jerks in their lower limbs were either absent of diminished, or "spastic" if (1) there was significant resistance to passive movement of the lower limbs accompanied by a visible muscle contraction which could be obtained on, at least, five successive stretches and (2) the tendon jerks in their lower extremities were exagge1 ated. Patients who did not fall clearly into either of these groups were classified as "intermediate."

\section{Neurophysiological examination}

Subjects lay prone with the leg to be examined immobilised in a padded frame with the knee extended and the 
ankle fixed at $90^{\circ}$. Compound muscle action potentials of triceps surae were recorded with surface electrodes. The active electrode was placed over the soleus muscle just distal to the tendinous insertions of the gastrocnemii. The indifferent electrode was placed $8 \mathrm{~cm}$ distally over the tendo Achilles and the ground was placed over the upper calf. The evoked muscle responses were amplified using standard electromyographic differential amplifiers (gain 200 to 2000 times) with band pass $10 \mathrm{~Hz}$ to $30 \mathrm{kHz}$. The peak to peak amplitudes of the muscle compound action potentials were measured from polaroid photographs. The duration of the negative (upward) peak was measured from the first deflection from the base line to the end of the negative phase.

The outputs of a Medical Systems Corporation dual high voltage stimulator (type 3072) were linked so that stimuli of different voltages could be delivered through the same bipolar electrode at selected intervals. The linkage did not significantly affect the delivered current from either stimulator at the settings used. The timing of the stimuli was controlled by a Digitimer 4030 . The reflex ( $\mathrm{H}$ reflex) and direct muscle ( $M$ response) responses were elicited using square wave stimuli, $0.5 \mathrm{~ms}$ duration, applied over the tibial nerve in the popliteal fossa. The position of the bipolar stimulating electrode was systematically adjusted in an attempt to obtain the $\mathrm{H}$ reflex at the lowest possible threshold and without any direct muscle response in the soleus or gastrocnemius muscles. The electrode was then immobilised by means of a rubber strap. The Achilles tendon reflex ( $T$ reflex) was elicited by supramaximal mechanical stimulation of the tendo Achilles using a manual hammer fitted with a switch which triggered the oscilloscope on contact. Vibration was applied to the tendo Achilles using a Wahl vibrator (frequency $60 \mathrm{~Hz}$, undamped amplitude $1.5 \mathrm{~mm})$.

\section{Procedure}

(a) $H$-M recruitment curve with and without vibration. The data for two complete $\mathrm{H}-\mathrm{M}$ recruitment curves (one with and one without vibration) were collected in the following manner. The stimulus current was increased in small increments until it was supramaximal for the $M$ response. After a control $\mathrm{H}$ reflex was obtained at each stimulus level, the vibrator was applied to the tendo Achilles for 20 seconds and the stimulus repeated during continuous vibration. A period of 90 seconds then elapsed before the net control response was elicited to avoid any delayed effects that could result from vibration.

(b) $H$ reflex conditioned by stimulus that just failed to excite motor axons. Two stimulators were now connected so that paired stimuli of different strengths could be delivered to the tibial nerve through the same electrode. The conditioning stimulus was set just below the threshold of the motor axons in the tibial nerve. This was established by inspection of the calf muscles and the EMG trace on the storage oscilloscope and was monitored during the experiment. An increase in the delivered current could be detected by the appearance of the $M$ response and a decrease by a reduction in the reflex response. The intention was to deliver a conditioning stimulus exciting as similar a proportion of the large muscle afferents as possible in every subject. The reflex response (Hs) to this standardised conditioning stimulus was recorded.

Trials were made every 30 seconds. The test stimulus was given alone (the control situation) or was preceded by a conditioning stimulus either 50 or $100 \mathrm{~ms}$ earlier. The test stimulus was increased in increments until the data for three complete $\mathrm{H}$-M recruitment curves (unconditioned control, condition-test interval $50 \mathrm{~ms}$ and condition-test interval $100 \mathrm{~ms}$ ) were obtained. The maximum conditioned $\mathrm{H}$ reflexes were then expressed as a percentage of the maximum unconditioned reflex.

(c) $H$ reflex conditioned by an afferent volley that was just subthreshold for an $\mathrm{H}$ reflex. The conditioning stimulus was now reduced until it just failed to produce an $\mathrm{H}$ reflex. Clearly if we reduced the stimulus too much we might excite no afferents at all. To avoid this we chose a stimulus level which (1) produced no $\mathrm{H}$ reflex with the subject at rest and (2) resulted in the reflex activation of a few motor units if the stimulus was slightly increased or if, where possible, the subject made a voluntary contraction of soleus. We also recorded whether (1) a small $\mathrm{H}$ reflex had occurred at any time during the study (as a result of spontaneous variations in the excitability of the motoneurone pool) or (2) the conditioning stimulus ever modified the response to the test volley (for example when the test stimulus and resulting $\mathrm{H}$ reflex were small). In most instances this documentation provided indirect evidence that the conditioning stimulus was not below the threshold of all the sensory nerve axons.

Trials were made every 30 seconds. The test stimulus was given alone (control situation), or was preceded by a conditioning stimulus 50 or $100 \mathrm{~ms}$ earlier. The test stimulus was increased in small increments until the data for three complete $\mathrm{H}-\mathrm{M}$ recruitment curves were collected the same way as before. The maximum conditioned $\mathrm{H}$ reflexes were expressed as a percentage of the maximum control $\mathrm{H}$ reflex.

(d) Achilles tendon reflex ( $T$ reflex). The response to three supramaximal reflex hammer blows to the Achilles tendon 5 seconds apart were recorded and their peak to peak amplitudes averaged.

\section{Statistical analysis}

The clinical and neurophysiological data were stored on computer files and analysed using standard statistical procedures including one-way and two-way analysis of variance and Tukey multiple range tests, Chi-square, $t$ tests and Pearson correlation coefficients. Probabilities (two tailed) of less than 0.05 were considered significant.

\section{Results}

In all, 104 successful studies were carried out on patients, 61 were on quadriplegics ( 29 with clinically complete and 32 with incomplete lesions) and 43 on paraplegics ( 29 clinically complete and 14 incomplete). The studies were made at intervals varying from 1 to 28 months after the spinal cord injury. 
Table 1 Neurophysiological data from normal subjects and patients with traumatic spinal cord injuries classified on clinical grounds as "flaccid", "intermediate", or "spastic". Number of observations in brackets. An asterisk indicates a significant difference $(p<0.05)$ from the normal data in the top row. An estimate of the area of the compound action potential recorded with surface electrodes over the soleus muscle in response to supramaximal stimulation of the tibial nerve ("M area") is reduced in all three of the patient groups. In patients classified as spastic the proportion of the triceps surae motoneuron pool activated by a tendon tap (T reflex/M\%) is greater, but the maximum $H$ reflex Mmax \% is not significantly different than normal. There is less suppression of the $\mathrm{H}$ reflex by vibration $(\mathrm{Hvib} / \mathrm{H} \%)$ in patients with spasticity.

\begin{tabular}{|c|c|c|c|c|c|}
\hline & & M Area (units) & $T$ reflex $/ M \%$ & $H \max \% / M$ & Hvib/H\% \\
\hline Normal subjects & & 117 & $\begin{array}{c}26 \\
(21)\end{array}$ & $\begin{array}{c}61 \\
(21)\end{array}$ & $\begin{array}{c}25 \\
(21)\end{array}$ \\
\hline Patients with cord lesions & $\begin{array}{l}\text { Flaccid } \\
\text { Intermediate } \\
\text { Spastic }\end{array}$ & $\begin{array}{c}53^{*} \\
(26) \\
69^{*} \\
(31) \\
73^{*} \\
(38)\end{array}$ & $\begin{array}{c}28 \\
(27) \\
30 \\
(33) \\
47^{*} \\
(39)\end{array}$ & $\begin{array}{c}50 \\
(27) \\
50 \\
(33) \\
70 \\
(39)\end{array}$ & $\begin{array}{c}36 \\
(21) \\
43 \\
(29) \\
61^{*} \\
(38)\end{array}$ \\
\hline
\end{tabular}

The $M$ response

The peak to peak amplitude of the $M$ response was significantly smaller in each of the patient groups than in normal subjects. To exclude the possibility that this was due to dispersion of the compound action potential (the duration of the negative peak was slightly longer in patients) an estimate of the area was calculated by multiplying the peak to peak amplitude by the duration of the negative peak. This "M area", which was expressed in arbitrary units, was also significantly smaller in each of the patient groups than in the normal subjects $(p<0.05)$ (fig 1 , table 1). The reduction in " $M$ area" was observed as early as 1 month after the lesion. The " $\mathrm{M}$ area" was smaller in those with complete spinal lesions (mean 54 "units") than in those with incomplete lesions (mean 81 "units") $(\mathrm{p}<0.05)$.

\section{$T$ reflex/M ratio}

The proportion of the motoneuron pool of triceps surae activated by an Achilles tendon tap (the $T$

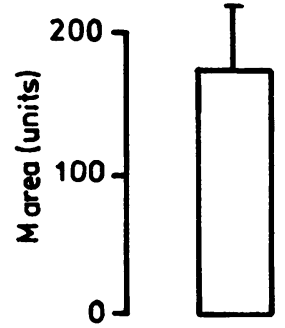

N

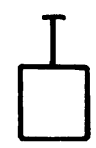

F

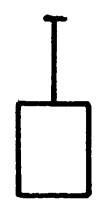

I

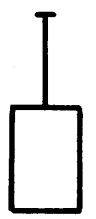

$\mathbf{S}$
Fig 1 Maximum compound action potentials of triceps surae in normal subjects $(N)$ and in patients with spinal lesions who were clinically flaccid $(F)$, intermediate $(I)$ or spastic $(S)$. The means and standard deviations of estimates (see text) of the areas of the compound action potentials are shown. The means for each of the patient groups are significantly smaller than the mean for the normal subjects.
reflex/M ratio) was significantly greater in the spastic group $(p<0.05)$ than in all other groups (table 1$)$. Within the spastic group this ratio was greater in patients with incomplete lesions than those with complete lesions $(p<0.05)$. The ratio increased with increasing duration of the lesion for all groups ( $\mathrm{r}=0.38 ; \mathrm{p}<0.001)$.

\section{$H \max / M$ and $H s / M$ ratios}

The largest proportion of the triceps suraes motoneuron pool that could be reflexly activated (the maximum $\mathrm{H} / \mathrm{M}$ ratio) was not significantly dif-o ferent from normal in any of the patient groupso (table 1). However, when a "standard" afferent volley (elicited by stimulating the tibial nerve just

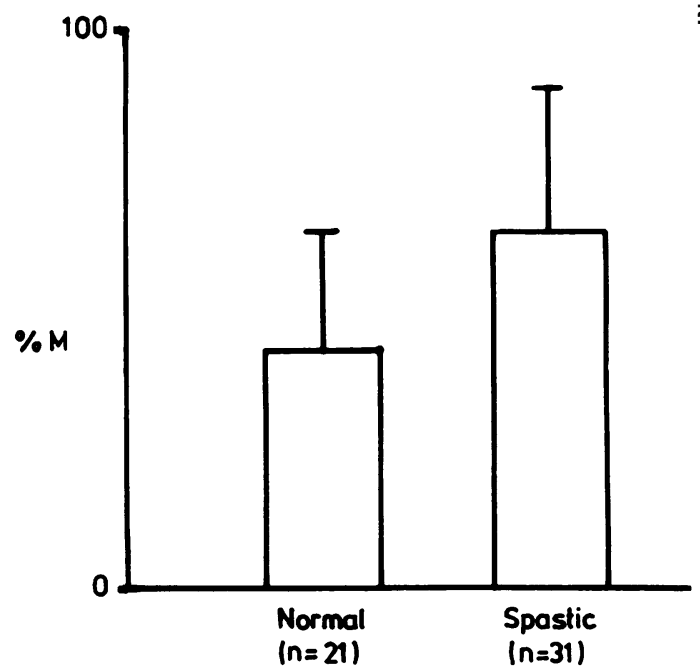

Fig 2 The proportion of the triceps surae motoneuron poo excited by a stimulus to the tibial nerve (just below the threshold of the alphamotoneuron axons) is significantly larger in patients with spinal spasticity than in normal subjects. Means and standard deviations shown. 
Table 2 Data from conditioning studies in normal subjects and patients with traumatic spinal cord lesions. Number of observations in brackets. An asterisk indicates a significant difference $(p<0.05)$ from the normal data in the top row. Using a conditioning stimulus which was just below the threshold from the alpha motoneuron axons (but suprathreshold for the $H$ reflex) the test $H$ reflex was greater in the patients classified as "intermediate" or "spastic" at both the 50 and 100 ms condition test intervals. When the conditioning stimulus was just subthreshold for an $H$ reflex there were no significant differences in the recovery of the test $H$ reflex between normal subjects and patients.

\begin{tabular}{|c|c|c|c|c|c|}
\hline & & \multicolumn{2}{|c|}{ Suprathreshold conditioning } & \multicolumn{2}{|c|}{ Subthreshold conditioning } \\
\hline & & H $50 / H \%$ & H $100 / H \%$ & H $50 / H \%$ & H $100 / H \%$ \\
\hline $\begin{array}{l}\text { Normal subjects } \\
\text { Patients with cord lesions }\end{array}$ & $\begin{array}{l}\text { Flaccid } \\
\text { Intermediate } \\
\text { Spastic }\end{array}$ & $\begin{array}{c}39 \\
(21) \\
61 \\
(14) \\
68^{*} \\
(19) \\
59^{*} \\
(31)\end{array}$ & $\begin{array}{c}58 \\
(21) \\
77 \\
(14) \\
85^{*} \\
(19) \\
91^{*} \\
(31)\end{array}$ & $\begin{array}{c}93 \\
(21) \\
101 \\
(13) \\
98 \\
(20) \\
98 \\
(29)\end{array}$ & $\begin{array}{c}94 \\
(21) \\
102 \\
(13) \\
99 \\
(20) \\
98 \\
(28)\end{array}$ \\
\hline
\end{tabular}

below the threshold of the alpha motoneuron axons) was used a greater proportion of the triceps surae motoneuron pool was excited in patients with spasticity $(64 \%)$ than in normal subjects $(43 \%$; p < $0 \cdot 01$ ) (fig 2).

\section{$H$-vib/H control ratio}

The ratio of the maximum $\mathrm{H}$ reflex during vibration to the maximum control $\mathrm{H}$ reflex ( $\mathrm{Hvib} / \mathrm{H}$ control ratio) was greater in the spastic group than in the normal or the other patient groups $(p<0.05)$ indicating that vibration was less effective in suppressing the $H$ reflex in the spastic patients (table 1).The $\mathrm{Hvib} / \mathrm{H}$ ratio increased with the duration of the

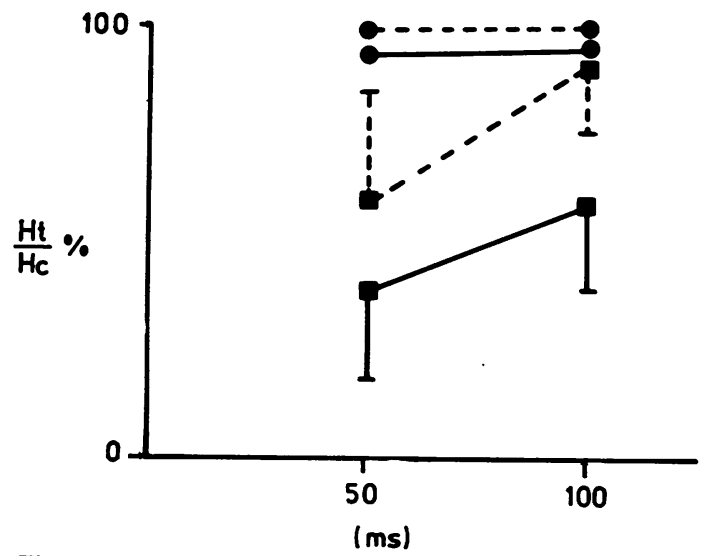

Fig 3 Recovery of the $\boldsymbol{H}$ reflex in normal subjects (solid lines) and patients with spinal spasticity (dashed line). When the conditioning stimulus is just below the threshold of the alphamotoneuron axons but sufficient to excite the motoneurons reflexly (filled squares) the recovery is faster in the patients with spasticity. When the conditioning stimulus is below the threshold for an $\mathrm{H}$ reflex (filled circles) there is no significant difference between the two groups. Means and standard deviations shown. lesion for all patients $(r=0.27 ; p<0.001)$, but was unrelated to the level of the lesion or to whether the lesion was complete or incomplete.

Conditioned $H$ reflex

Satisfactory conditioning studies were completed on 64 occasions. When the conditioning stimulus was just below the threshold of alpha motoneuron axons, the maximum $\mathrm{H}$ test/H control ratio 50 and $100 \mathrm{~ms}$ later was greater in the patients with spasticity (and in the intermediate group) than in normal subjects (table 2). These ratios showed a weak positive correlation with duration of lesion. When the conditioning stimulus was just subthreshold for the production of an $\mathrm{H}$ reflex, however, there were no differences between the normal subjects and patients (fig 3, table 2).

The first type of conditioning volley used results in an $\mathrm{H}$ reflex. Does the muscle contraction produced by this conditioning volley influence the $\mathrm{H}$ reflex recovery curve? In separate experiments on ten normal subjects we conditioned the $\mathrm{H}$ reflex with a muscle contraction produced by stimulating the triceps surae directly. There was no significant alteration in the test $\mathrm{H}$ reflex amplitude until the conditioning-test interval was greater than $70 \mathrm{~ms}$. The $\mathrm{H}$ reflex was then depressed. It thus appears that the afferent barrage resulting from a previous muscle contraction has no influence on the $H$ reflex at the $50 \mathrm{~ms}$ condition-test interval although it could contribute to the depression of the $H$ reflex at the $100 \mathrm{~ms}$ interval.

\section{Discussion}

The muscle compound action potential

The maximum muscle compound action potentials were smaller in the patients with spinal lesions espe- 
cially when the spinal lesion was clinically complete. This has been noted before in triceps surae ${ }^{8}$ and in a small muscle of the foot. ${ }^{13}$ The reduced electrical signal may be partly due to the disuse atrophy of muscle fibres which follows upper motor neuron lesions ${ }^{14-16}$ but motor unit counts have shown a reduction in the number of functioning motor units in muscles below a spinal lesion in man. ${ }^{17}$

\section{Tendon jerk and $H$ reflex}

The proportion of the triceps surae motoneuron pool activated by an Achilles tendon tap ( $T$ reflex/M ratio) was increased in the patients with spasticity but the largest proportion of this motoneuron pool which could be reflexly activated electrically (Hmax/M ratio) was not. This situation has been described in spasticity from mixed and cerebral lesions $^{5-18}$ with the suggestion that the disproportionate increase in the tendon jerk might reflect a change in spindle excitability. However, we found that a standardised electrical stimulus to the tibial nerve (just below the threshold of the alpha motoneuron axons) also reflexly activated a larger proportion of the triceps motoneuron pool in patients with spasticity than in normal subjects. One possible explanation for these findings is that in spasticity there is an increase in the excitability of whatever central pathways are common to the tendon jerk and the $\mathrm{H}$ reflex, but that the maximum $\mathrm{H}$ reflex normally excites such a large proportion of the motoneuron pool that little further increase is possible. An increase in central excitability could result from alterations in the properties of the presynaptic pathway, the ease of which motoneurons are recruited or the state of interneurons capable of influencing motoneurons. We now tried to distinguish between these possibilities.

\section{Suppression of the $H$ reflex by vibration}

In normal subjects vibration of a limb causes a striking depression of the $\mathrm{H}$ reflex. ${ }^{19-21}$ The depression occurs some time after the onset of vibration and may outlast the vibration by several hundred $\mathrm{ms},{ }^{22}$ so it is unlikely to be due to occlusion in the afferent nerve fibres (the "busy line" effect). Vibration also suppresses the facilitation of single motors unit by group 1 volleys without changing the motor units firing rate (and, by implication, its excitability). ${ }^{23}$ If the $\mathrm{H}$ reflex is accepted as being largely mediated by a monosynaptic pathway, the locus of the suppressive effect of vibration is "premotoneuronal" (for example, due to presynaptic inhibition, transmitter depletion of failure of invasion of some afferent terminals).

Vibration produces less depression of the $\mathbf{H}$ reflex in patients with spasticity ${ }^{1820}$ and we confirm that this is also the case for a large group of patients with spasticity from spinal lesions. Either the mechanisms which normally block the $\mathrm{H}$ reflex (see above) are less effective in spasticity or vibration produces a greater background facilitation of motoneurons in spasticity. The latter explanation is not supported by the findings of Sommerville and Ashby. ${ }^{23}$

\section{Conditioning studies}

We explored the excitability of the presynaptic and postsynaptic segments of the $\mathrm{H}$ reflex pathway by using conditioning volleys that excited the motoneurons and conditioning volleys that just failed to do so. There are several variables that must be controlled in such conditioning experiments. The strength of the test stimulus is critical. A small test $\mathrm{H}$ reflex is more affected by conditioning volleys than a large one..$^{24}$ To overcome this difficulty we plotted the entire $\mathrm{H}-\mathrm{M}$ recruitment curve at each conditioning-test interval and chose only the largest control and conditioned $\mathrm{H}$ reflexes.

The strength of the conditioning stimulus is also crucial. The stronger the conditioning stimulus the greater the inhibition of the $\mathrm{H}$ reflex..$^{2426}$ As this is due, in part, to inhibitory effects arising from the stronger conditioning volley, ${ }^{27}{ }^{28}$, we chose a conditioning volley just below the threshold for motoneuron axons in order to excite as similar a population of afferents as possible in the normal subjects and spastic patients. Motor and sensory conduction velocities do not change in these patients ${ }^{17}$ so the relative thresholds can .be assumed to be similar to those in normal subjects. We found that the test $\mathrm{H}$ reflex (expressed as a percentage of control) was larger in spastic patients at intervals of $50 \mathrm{~ms}$ and $100 \mathrm{~ms}$ following such conditioning volleys (fig 3). This has also been reported in spasticity from cerebral and mixed lesions. ${ }^{234729}$ The refractory period of afferent nerve fibres is known to be very short and can be neglected as contributing to $\mathrm{H}$ reflex depression. The larger $\mathrm{H}$ reflex in spastic patients following a conditioning volley could result from more rapid recovery of excitability of the presynaptic terminals or of the population of motoneurons or from changes in the late arriving synaptic activity arising from the conditioning volley (or from the consequent muscle contraction).

We tested transmission in the presynaptic segment of the $\mathrm{H}$ reflex pathway by conditioning the $\mathrm{H}$ reflex with an electrically induced afferent volley just insufficient to excite the motoneurons reflexly, but presumably still sufficient to excite some of the large afferents and their presynaptic terminals. There were no significant differences between the normal subjects and spastic patients. Thus the presynaptic changes produced by a single volley are 
inadequate to explain the observed changes in $\mathrm{H}$ reflex recovery cycle, even though conditioning with multiple mechanically induced afferent volleys (vibration) appears to reveal changes in presynaptic transmission in spasticity. The faster recovery of the $\mathrm{H}$ reflex in the spastic patients must be explained either by increased excitability of motoneurons or by changes in late arriving synaptic activity resulting from the conditioning volley. We cannot distinguish between these possibilities in the present study.

Teasdall $e a^{l^{30}}$ observed late responses to muscle stretch in the chronic hemisected cat implying altered excitability in interneuronal pathways and Dimitrijevic and Nathan" reported prolongation of the action potential resulting from a tendon tap. For this reason, we looked carefully at the action potentials resulting from tendon taps in our patients. There were no late inflections or waves following the main complex to suggest polysynaptic activation of motoneurons.

Could any of the present findings be explained by an alteration in the motor units of triceps surae? For example, if there was a selective atrophy of type II, phosphorylase rich, muscle fibres-which has been described in spasticity following hemisphere lesions, ${ }^{18}$ although not consistently following spinal lesions in $\operatorname{man}^{14}{ }^{31}$ or animals, ${ }^{3233}$ the neurophysiological properties of motor units innervating type I fibres might dominate the recordings. Motoneurons innervating slow twitch fibres have higher input resistances and larger EPSPs. ${ }^{34}$ Their predominance in spastic patients could account for a higher $T$ reflex/M ratio. However, these motoneurons have longer afterhyperpolarisation ${ }^{34}$ and this would tend to delay the recovery of the $\mathrm{H}$ reflex following a conditioning volley. Thus, a selective loss of a population of motoneurons or atrophy of their muscle fibres cannot provide a satisfactory explanation for all the present findings.

We thank the Physician's Services Incorporated, the Multiple Sclerosis Society of Canada, and the Medical Research Council of Canada for financial support, the physicians of Lyndhurst Hospital for their cooperation, the Health Care Unit, University of Toronto for statistical analyses.

\section{References}

' Lance JW. Symposium Synopsis. In: Feldman RG, Young RR, Koella WP (eds): Spasticity: Disordered Motor Control; Chicago, Year Book Medical Publishers, 1980:485-94.

${ }^{2}$ Magladery JW, Teasdall RD, Park AM, Languth HW. Electrophysiological studies of reflex activity in patients with lesions of the nervous system. 1. A com- parison of spinal motoneurone excitability following afferent nerve volleys in normal persons and patients with upper motor neuron lesions. Bull Johns Hopkins Hosp 1952;91:219-44.

${ }^{3}$ Zander Olsen P, Diamantopoulos E. Excitability of spinal motor neurones in normal subjects and patients with spasticity, Parkinsonian rigidity, and cerebellar hypotonia. J Neurol Neurosurg Psychiatry 1967;30:325-31.

${ }^{4}$ Takamori M. H-reflex study in upper motoneuron diseases. Neurology (Minneap) 1967;17:32-40.

5 Dietrichson P. Phasic ankle reflex in spasticity and Parkinsonian rigidity. The role of the fusimotor system. Acta Neurol Scand 1971;47:22-51.

${ }^{6}$ Hagbarth KE, Wallin G, Lofstedt L. Muscle spindle responses to stretch in normal and spastic subjects. Scand J Rehabil Med 1973;5:156-9.

${ }^{7}$ Strassburg HM, Oepen G, Thoden V. The late facilitation in H-reflex recovery cycles in different pyramidal lesions. Arch Psychiat Nervenkr 1980;228: 197-204.

${ }^{8}$ Weaver RA, Landua WM, Higgins JF. Fusimotor function. Part II. Evidence for fusimotor depression in human spinal shock. Arch Neurol 1963;9:127-32.

${ }^{9}$ Diamantopoulos E, Zander Olsen P. Excitability of motor neurones in spinal shock in man. $J$ Neurol Neurosurg Psychiatry 1967;30:427-31.

${ }^{10}$ Dimitrijevic MR, Nathan PW. Studies of spasticity in man. 1. Some features of spasticity. Brain 1967;90: 1-30.

" Dimitrijevic MR, Nathan PW. Studies of spasticity in man. 2. Analysis of stretch reflexes in spasticity. Brain 1967;90:333-58.

12 Ashby P, Verrier M. Neurophysiological changes following spinal cord lesions in man. Can J Neurol Sci 1975;2:91-100.

${ }^{13}$ Taylor RG, Kewalramani LS, Fowler WM. Electromyographic findings in lower extremities of patients with high spinal cord injury. Arch Phys Med Rehabil 1974;55:16-23.

${ }^{14}$ Brooke MH, King Engel W. The histographic analysis of human muscle biopsies with regard to fiber type. 2 . Diseases of the upper and lower motor neuron. Neurology (Minneap) 1969;19:378-393.

${ }^{15}$ Edstrom L. Selective changes in the sizes of red and white muscle fibres in upper motor lesions and Parkinsonism. J Neurol Sci 1970;11:537-50.

${ }^{16}$ Reske-Nielsen E, Harmsen A, Ovesen N. Pathological study of muscle biopsies from the legs in patients with fractures of the cervical spine. In: Actualities de Pathologie Neuromusculaire; Paris, Expansion Scientifique, 1971:509-21.

${ }^{17}$ Hunter J, Ashby P. Secondary changes in segmental neurons below a spinal cord lesion in man. Arch Phys Med Rehabil 1984; (in press).

${ }^{18}$ Buller AJ. The ankle-jerk in early hemiplegia. Lancet 1957; 2:1262-3.

${ }^{19}$ Lance JW, Burke D, Andrews CJ. The reflex effects of muscle vibration. Studies of tendon jerk irradiation, phasic reflex inhibition and the tonic vibration reflex. In: Desmedt JE (ed): New Developments in Electromyography and Clinical Neurophysiology; Basel, Karger, 1973, Vol. 3, 444-62. 
${ }^{20}$ Delwaide PJ. Human monosynaptic reflexes and presynaptic inhibition, In: Desmedt JE (ed). New Developments in Electromyography and Clinical Neurophysiology; Basel, Karger, 1973, Vol. 3, 44462.

${ }^{21}$ Ashby P, Verrier M, Carleton S, Somerville J. Vibratory inhibition of the monosynaptic reflex and presynaptic inhibition in man. In: Feldman RG, Young RR, Koella WP (eds). Spasticity: Disordered Motor Control; Chicago, Year Book Publishers, 1980:335-44.

${ }^{22}$ Somerville J, Ashby P. Hemiplegic spasticity. neurophysiological studies. Arch Phys Med Rehabil 1978;59:592-6.

${ }^{23}$ Ashby P, Verrier M. Human motoneuron responses to group 1 volleys blocked presynaptically by vibration. Brain Res 1980;183:511-6.

${ }^{24}$ Paillard J. Analyse electrophysiologique et comparaison, chez l'homme, du reflexe de Hoffmann et du reflexe myotatique. Pftuegers Arch 1955;260:448-79.

${ }^{25}$ Meinck HM. Facilitation and inhibition of the human $\mathrm{H}$ reflex as a function of the amplitude of the control reflex. Electroencephalogr Clin Neurophysiol 1980;48:203-11.

${ }^{26}$ Magladery JW, Teasdall RD, Park AM, Porter WE. Electrophysiological studies of nerve and reflex activity in normal man. V. Excitation and inhibition of two-neurone reflexes by afferent impulses in the same nerve trunk. Bull Johns Hopkins Hosp 1951;88:521-37.
${ }^{27}$ Trontelj JV. A study of the H-reflex by single fibre EMG.J Neurol Neurosurg Psychiatry 1973;36:951-9.

${ }^{28}$ Kots YM. The Organization of Voluntary Movement. New York, Plenum Press, 1977.

${ }^{29}$ Yap CB. Spinal segmental and long-loop reflexes on spinal motoneurone excitability in spasticity and rigidity. Brain 1967;90:887-96.

${ }^{30}$ Teasdall RD, Villablanca J, Magladery JW. Reflex responses to muscle stretch in cats with chronic suprasegmental lesions. Bull Johns Hopkins Hosp 1965; 116:229-42.

${ }^{31}$ Edstrom L, Grimby L, Hannerz J. Correlation between recruitment order of motor units and muscle atrophy pattern in upper motoneurone lesion. significance of spasticity. Experientia 1973;29:560-1.

${ }^{32}$ Karpati G, King Engel W. Correlative histochemical study of skeletal muscle after suprasegmental denervation, peripheral nerve section and skeletal fixation. Neurology (Minneap) 1968;18:681-92.

${ }^{33}$ Klinkerfuss GH, Haugh MJ. Disuse atrophy of muscle: histochemistry and electron microscopy. Arch Neurol 1970;22:309-20.

${ }^{34}$ Burke RE. Motor units: anatomy, physiology, and functional organization. In: Brookhart JM, Mountcastle VB (eds). Handbook of Physiology. Baltimore, Williams and Wilkins, 1981. Section 1, The nervous system, Vol 2, Motor control, Part 1, 345-422. 